Published in: Hakulinen, Auli / Selting, Margret (eds.): Syntax and lexis in conversation. Amsterdam: Benjamins, 2005. p. (289)-317.

\title{
Conversational interpretation of lexical items and conversational contrasting ${ }^{\star}$
}

\author{
Arnulf Deppermann \\ Johann Wolfgang Goethe-University Frankfurt am Main
}

\begin{abstract}
One major issue in the accomplishment of contrasts in conversation is lexical choice of items which carry the semantic load of the two states of affair which are represented as being opposed to one another. These items or expressions are co-selected to be understood as being contrastively related to each other. In this paper, it is argued that the activity of contrasting itself provides them with a specific local opposite meaning which they would not obtain in other contexts. Practices of contrasting are thus seen as an example of conversational activities which creatively and systematically affect situated meanings. Based on data from various genres, such as meetings, mediation sessions and conversations, the paper discusses two practices of contrasting, their sequential construction and their interpretative effects. It is concluded that the interpretative effects of conversational contrasting rest on the sequential deployment of linguistic resources and on the cognitive procedures of frame-based interpretation and constructing a maximally contrastive interpretation for the co-selected expressions.
\end{abstract}

\section{Introduction}

Contrast is one of the most fundamental semantic relations between lexical items. While lexical semantics conceives of contrasts as structural sense relations which hold context-free, ethnomethodology, conversation analysis and interactional linguistics are interested in how contrasts are achieved in discourse by participants' work. Research so far has mainly focused on the sequential organization of contrasts, their prosody and their discursive functions and inferential properties. Another major issue in the accomplishment of contrasts in conversation is lexical choice - the choice of words and phrases which are contrasted and which carry the semantic load of the two states of affair that are represented as being opposed to one another. These items, however, are only rarely related to one another in terms of lexico-semantic contrast (such as small vs. large; buy vs. sell). But how does lexical choice then relate to activities of contrasting? In this paper, I argue that activities of contrasting often affect the currently relevant interpretation of the contrasted lexical items. It can provide them with a lo- 
cal meaning which they would not obtain in other contexts. To be more specific, the activity of contrasting suggests an interpretation of the contrasted words as local opposites. This most prominently involves that semantic and inferential properties which are locally contingent on the first of the contrasted items are negated or corrected by the second one. Contrasting thus focuses on and defocuses specific semantic aspects, it instructs the selection among and the inference to local interpretations, and it leads to the ad hoc construction of local taxonomic relations. In this way, activities of contrasting can provide lexical items with a local meaning which, by repeated, routine use, may be strongly associated with them. It can become part of their meaning potential and can therefore also be deployed in other, non-contrastive contexts of use. After a short review of research on contrasts and contrasting (Section 2) and a note on data and method (Section 3), I will discuss two practices of conversational contrasting which differ in their sequential and functional organization as well as in aspects of their semantic impact on the contrasted words (Sections 4 and 5). Building on these analyses, I will claim that there are two interpretive strategies which participants use for the local specification of word-meanings by activities of contrasting: frame-based interpretation and maximization of contrast (Section 6).

\section{Approaches to contrasting}

Contrast is one of the main topics of structural lexical semantics (e.g. Cruse 1986; Lyons 1977). It is studied as one paradigmatic property of the relation between lexical items as such. The relation of contrast holds for any two lexical items which can be mapped onto a common semantic dimension and which

- simply exclude one another (incompatibility: Monday vs. Tuesday);

- inhabit polar positions on a dimensional scale ((polar) antonymy: hot vs. cold);

- divide a common dimension into two sections and negatively imply one another (complementarity: dead vs, alive);

- denote states or processes which are spatially or temporally opposed to one another (perspectival conversion: before vs. after), reciprocal actions or roles in action sequences (e.g. buy vs. sell), or opposing directions and actions (directional conversion: come vs. go; restitutives: gain vs. waste).

Although some structuralists concede that there may be some "contextual modulation" (Cruse 1986:51ff.), which modifies the meaning of an item, the specification of meaning in contexts of use is no essential concern for them and is not systematically accounted for in their semantic models. The lexicon is conceived of as an inventory of static, context-free relations. Accordingly, contrast is a sense-relation between decontextualized items. Structuralists do not ask what conversationalists themselves mark and treat as contrasting. Activities of contrasting and their interpretation in real interactional contexts are not considered as the proper object of semantic study. Consequently, effects of discursive activities on the semantics of individual lexical items are 
not taken into account. Therefore, this view cannot provide for systematic origins of polysemy and semantic change. ${ }^{1}$

Studies in syntax and text linguistics inquire into contrast as a relation which holds between propositions. It is expressed by clauses or sentences (e.g. Rudolph 1996), or, more generally, exists between segments of texts (Mann \& Thompson 1992). Although most studies focus on the propositional level, contrasts can also be established on the epistemic or speech act level (Sweetser 1990), and even on the textual level. In syntactic, text and interactional linguistic studies, definitions of contrast range from very restrictive conceptions to a notion of 'contrast' as a super-category for a variety of more specific relations (see e.g. Mann \& Thompson 1992; Rudolph 1996).

In this paper, a rather broad conception of 'contrast' as a cover-term will be adopted: Following Barth-Weingarten (2003:39), "contrast is understood here as a general term for all kinds of relations which in some way express an opposition between items of one sort or another:" This definition neither unduly restricts the size of discursive segments to be contrasted nor makes any premature suppositions about linguistic means, the level and semantic features of the contrast. This wide definition of 'contrast' includes more specific concepts that are well known:

- Adversativity: In its dialogical realization, adversativity is prototypically realized by a first speaker making a claim which a second speaker straightforwardly objects to (ex.: A: "People told me you were at home." B: "But not at that time.")

- Neutral contrast does not involve a preference for one part of the contrasted items, but "two items are said to be in contrast if they are comprehended to be the same in many respects, comprehended as differing in a few respects, compared with respect to one or more of these differences" (Mann \& Thompson 1992: 37; ex.: A: "Yesterday, I knew the whole book by heart, but when they asked me, I didn't remember anything.").

- Concession as a discursive-pragmatic relation is prototypically realized according to a tripartite 'Cardinal Concessive Schema' with a first speaker making a claim $\mathrm{X}$ which, in contrast to adversativity and neutral contrast, a second speaker first concedes $\left(X^{\prime}\right)$ and then counters with Y (Couper-Kuhlen \& Thompson 2000; Barth-Weingarten 2003; ex.: A: "Yesterday was a real downer." B: "That's true, but you have to learn to put up with such things."). The concession may involve an irrelevant or a potential obstacle to the validity of a claim, "negated causality" (König \& Siemund 2000), i.e. a cause-effect-relation does not hold in the specific case, or a restriction of the validity or generality of a statement (Günthner 2000).

- Antithesis: In contradistinction to other contrastive relations, antithesis involves the negation of $X$ which is contrasted with the affirmation of $Y$ (Thompson \& Mann 1987). The Cardinal Antithesis Schema thus consists of a first speaker making some claim $X$ which a second speaker denies and supplants with a counterclaim Y (ex.: A: "You have slandered me!" B: "No. It was you who slandered me!").

Interactional linguistics is not only concerned with aspects of formal sequential organization and linguistic marking, but also with interactional functions and conse- 
quences. Ford $(2000,2001)$ showed that in interaction, a variety of (adversative and antithetic) contrasts are treated as being in need of explanation, solution or correction. As an exception to this, she refers to cases of trouble-telling and authority-based interaction where such a treatment was not wished or not granted. Barth-Weingarten (2003: Ch. 5) concludes that concession in interaction may operate on the ideational, interpersonal and textual level. Thus, it not only serves to increase the acceptability of a counter-move, but even more often establishes grounds for a disruptive (interrupting, topic changing etc.) move.

In conversation analysis (CA) and ethnomethodology, contrasts or contrast structures are regarded as a routine practice for the rhetorical organization of descriptions (Edwards 1997). There are, however, only few studies which explicitly focused on contrasts. The forms and uses of contrasts identified are rather varied, though. Smith (1978) has shown how contrast structures are used to account for a person's categorization as 'mentally ill'. Here, contrasts are made up by deviations from norms of adequate behaviour and from action preferences established by the teller. Atkinson's (1984) analyses of political oratory reveal how contrasts are designed as clap traps. These contrasts mainly rely on patterns of repetition and variation, both syntactically and prosodically. Drew (1992) investigated contrasting descriptions in courtroom-examinations. He shows how lawyer and witness select competing categorizations of the same events or behaviours. These contrasts are used as other-corrections and designed to make available competing inferences regarding motives, responsibility and guilt of the actors in question. Building on these analyses, Edwards (1997 and 1998) highlights the rhetoric, situated and pragmatic design of contrasts in text and talk, especially in competitive or argumentative contexts. He claims that contrast structures are "not just a matter of deploying ready-made conceptual resources that are built into semantic categories, but something people can do flexibly and inventively, for just about any set of objects or events" (Edwards 1997:237). The thrust of Edwards' quote runs counter lexico-semantic conceptions of interactional meaning: He sees the activity of presenting things as contrasting as primary and as independent of lexical contrasts. Contrast structures in discourse neither depend on lexical givens nor do they reflect brute, naturalistic (or experiential) facts. It is rather a pragmatically designed rhetoric move to organize things into binary contrasts and to present them as (the relevant, the only possible etc.) alternatives. Edwards' pragmatic approach contrasts with authors who, in the framework of traditional semantics, have claimed that "semantic opposition" (Lakoff 1971) of minimally two pairs of corresponding lexical items in X and Y may be the source of the contrast between X and Y (see also Longacre 1983: 83). Lakoff's illustrative sentence John is rich but Bill is poor for example involves a pair of incompatibles (John vs. Bill) and a pair of polar antonyms (rich vs. poor). In this approach, semantic opposition is regarded as a lexical fact which exists prior to and independently of discourse and is used as a resource to build a textual (propositional) opposition.

Lexical contrasts are not necessary to achieve discursive contrasts, although there are subtypes which involve semantic opposition, one being neutral contrast (see above). If a discursive contrast, however, crucially rests on a contrast between two (or 
more) corresponding lexical items, it is (at least tacitly) assumed that their contrastivity is lexically driven, i.e., that it is given beforehand by a context-free structural relation of the items. Their contrastivity would thus only be used in talk-in-interaction, but not established by talk-in-interaction itself. In this paper, however, I intend to show that the latter case is pervasive: It is by activities of contrasting that conversationalists provide pairs of lexical items or phrases with a situated, semantically contrastive interpretation which they would not obtain in isolation, i.e. without being part of the discursively achieved contrast structure. It will be shown that these situated meanings may sometimes clearly differ from established lexical meanings. The latter, however, need, at least to some extent, to be seen as sedimentations of frequent activities of contrasting of particular lexical items in discourse.

As this selective overview of the literature already suggests, contrasting is no homogeneous practice: Linguistic marking, sequential organization, interactional function, level of contrast and the exact discourse-pragmatic relation of the stretches of talk that are contrasted with one another are quite manifold. It will not come as a surprise that practices of contrasting also differ in terms of how the local interpretation of contrasted items is affected by the activity. After a short note on my data and the method of analysis (Section 3), I will discuss two different practices of contrasting which can provide contrasted lexical items (or phrases) with a specific, situated interpretation: One is "correcting a prior categorization" (Section 4), the other is "warranting a deviationcategorization" (Section 5). These two practices differ in their linguistic realizations, sequential and functional organization, and, what matters most here, they also involve different interpretive devices to establish the situated meaning of the contrasted items. At the same time, however, it will be shown that there are still more general interpretive strategies which are shared by both practices (Section 6).

\section{Data and method}

My study on contrasts is based on a corpus covering a range of interactional situations: five leisure time conversations among adolescents, one family dinner table conversation, one planning session for a radio show, three mediation sessions, one biographical interview and four political lectures with discussion in public places. Thirty instances of interactionally achieved contrasts were analyzed in detail. The sequential analysis proceeded in a conversation analytic manner, with special emphasis on the following issues:

- How is a contrast achieved and displayed (syntactically, prosodically)?

- How is it sequentially organized? When and by whom is the contrast established? How is it reacted to?

- Which words or phrases are contrasted?

- How does the contrast affect the local interpretation of the contrasted items and how are they semantically related to each other? 
- Is there specific background knowledge contextualized which is relevant for the understanding of the contrast?

- What is the function of the contrast in the interactional sequence?

Since this study specifically deals with the effects of conversational activities on the local interpretation of words and phrases, issues of semantic structure and conversational inference gained major importance. It therefore became necessary to introduce some cognitive concepts, namely 'background knowledge', 'frame-based expectation' and 'maxims of interpretation', to account for the details of the local use and interpretation of contrasts.

4 .

Disaffiliative reactions, such as disagreement, objection or other-correction, pertain to a variety of things made relevant by a prior speaker's turn, e.g. propositional content, opinions/assessments, lexical choice, compliance with a projected course of joint or next speaker's action etc. Disaffiliation can be specifically directed to a prior speaker's use of a specific word (or phrase): Next speaker displays that s/he does not accept prior speaker's interpretation of the word as locally adequate. Here is an example from a meeting of adolescents planning a broadcast-show and discussing its contents. ${ }^{2}$ Ken proposes that the group should play music for half an hour; Michaela objects that the music should not be played in one piece: ${ }^{3}$

(1) halbe stunde (broadcast meeting)

$01++$ Ke: Ich würd ma sagen so halbe stunde mUsik

I would say play about half an hour of

02 auflegen-

music-

$03 \rightarrow \mathrm{Mi}: \quad<\mathrm{ff}>$ ja aber net am ganzen stück.>

$<<f f>$ yes but not in one piece. $>$

04 Ma: ((laughs))

$05 \rightarrow$ Mi: [zwisch=durch auch- (.) weißt schon

[in between also- (.) you know

06 (was ich mein)]

(what I mean) I

07 Ra: [NEE: : :; ]

[NO:::; ]

08 Ke: [EIJA äh ja ( ) nich so-]

[well aye (') not so- ]

$09 \rightarrow \mathrm{Mi}$ : also AUFgeteilt irgendwie, (.)

I mean split up somehow, (.)

After a short agreement token, Michaela refuses a potential interpretation of Ken's proposal (line 2): The music should not be played in one piece. In what follows, she clar- 
ifies her objection by formulating the interpretation of Ken's proposal that she would accept: There had to come something (i.e. talk) in-between (line 5), that is, the music had to be split up (aufgeteilt, line 9). There is thus the contrast between a (potential) continuative interpretation of halbe stunde ('half an hour'), which Michaela rejects, and a discontinuative interpretation, which she favours. Ken immediately shows in line 8 that he accepts the discontinuative interpretation. So, the contrast achieves two different interpretations of halbe stunde:

a. Exposure: The contrast exposes a possible interpretation of halbe stunde as it was used by the prior speaker Ken. Michaela points to the fact that halbe stunde may have a continuative interpretation which is not acceptable from her point of view. The contrasted phrase net am ganzen stïck ('not in one piece') negates (inferential) aspects of a possible interpretation of halbe stunde as used by Ken. This is, net am ganzen stiick makes aspects of the interpretation of halbe stunde explicit which Ken did not formulate, but which Michaela attributes to Ken's (possible) interpretation. By rejecting a possible interpretation made available by his turn, Michaela suggests two alternative inferences: Either Ken must have had the interpretation she objects to, or he has failed to be as precise as necessary and thus risked a potential misunderstanding because of ambiguity or vagueness.

b. Correction: The contrasted item net am ganzen stïck supplants Ken's possible continuative interpretation of halbe stunde - which Michaela does not accept - with a discontinuative interpretation (which she prefers).

In a corrective contrast-sequence, then, the adequacy ${ }^{4}$ of the use and the semantics of a word in a prior speaker's turn is at issue. A second speaker expresses his/her rejection by contrasting the prior speaker's formulation (FO) with a second formulation (CO) which in some aspect opposes to FO. Thus, the basic schema is a dialogically achieved contrast structure:

S1: FO

S2: (FO) but $\mathrm{CO}$

\subsection{Asymmetric contrast of perspectives and nested interpretation}

The corrective contrast objects to the adequacy of a prior speaker's formulation by multiplying its interpretations. There are three interpretations of the formulation at issue which are involved in a dialogical corrective contrast:

a. Prior speaker's own interpretation of FO in his/her own turn. In (1), Ken's own interpretation of halbe stunde might be continuative as well as discontinuative.

b. Next speaker's interpretation of how prior speaker has or might have interpreted $\mathrm{FO}$, that is, next speaker's exposure of a (possible) interpretation of FO. In (1), Michaela exposes the possible continuative interpretation of halbe stunde. 
c. Next speaker's corrective interpretation of FO, that is, next speaker introduces a contrasting interpretation which s/he proposes to be more adequate. In (1), the next speaker favours the discontinuative interpretation of halbe stunde by rejecting the continuative interpretation (aber net am ganzen stück; 'but not in one piece').

(a) and (b) must be kept apart, because (b) is not a direct, but a nested representation: Next speaker's exposition of prior speaker's interpretation of FO may not be accepted by him/her as a correct rendering of his/her intentions. This phenomenon is well-known from arguments. In excerpt (1), Ken accepts the correction (line 8) and seems to concede that he could have been understood as meaning a continuative interpretation of halbe stunde. Formulating a corrective contrast to a prior speaker's formulation is not only a way of (re-)specifying its meaning; it is also a way of expressing a (supposed) contrast of participants' perspectives. The activity of contrasting here creates two discursively relevant mental spaces (cf. Fauconnier 1985) which contain different readings of the target formulation - next speaker's own interpretation and his/her alter-representation of prior speaker's interpretation. These two interpretations are asymmetrically ordered with respect to the interactional process and to their evaluation. While the alter-representation reveals a backward looking, context-bound (Heritage 1995) understanding of the prior turn, which is denied, next speaker's own interpretation is a forward looking, context-renewing (Heritage 1995) interpretation, which is presented as the preferred basis for further talk. The inquiry into the semantic workings of the corrective contrast shows that the adversative or concessive relation 'FO but CO' essentially hides an antithetic relation 'Not $\mathrm{FO}$ as understood by prior speaker but FO as understood by next speaker' and thus an asymmetric ordering of conflicting perspectives.

I will present some further cases to provide an impression of the generality of corrective contrasts. Excerpt (2) is from an argument between mediator and proponent in a mediation session. ${ }^{5}$ The mediator claims that the proponent had complained that her opponent's daughter threw stones at clothes hanging in their common yard. The proponent denies to have made this complaint. Excerpt (2) starts with the mediator insisting on the truth of his quote by referring to the official record of the complaint. The proponent then tries to resolve the conflict and claims that the child threw stones, but did not hit clothes.

(2) schmeißt [Mediation; IDS-Mannheim 'Schlichtung' 3001/02]

Med: da ham sie awwer $\mathrm{AUCH}-($.

there you have also- (.)

02 angegebe wie die TocHter der Antragsgegnerin auf declared how the daughter of the opponent on dem <<len, ubberdeutlich prononciert> geMEINsamen the $<<$ len, overarticulate $>$ common wäschetrockenplatz einen stein auf die wäsche laundry drying ground 


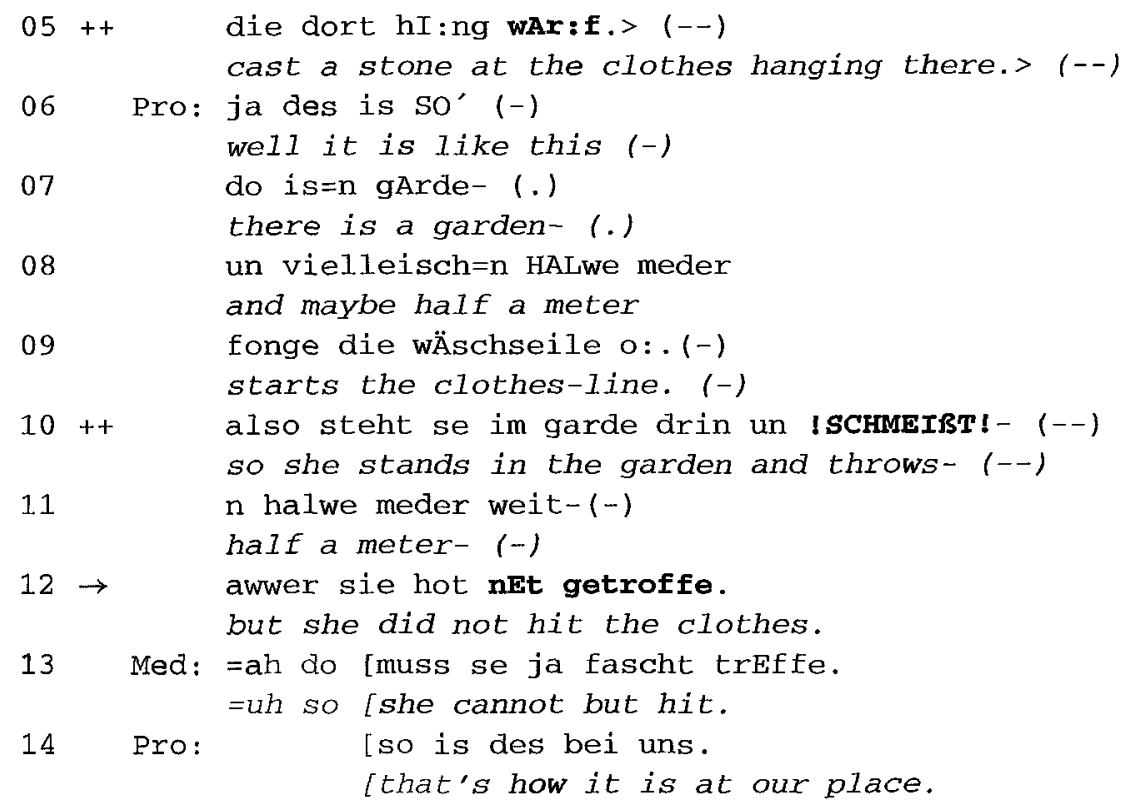

The mediator confronts the proponent with a contradiction: Before the excerpt starts, the proponent denied a fact which she previously had declared to be true (cf. lines 15). The proponent tries to resolve this (alleged) contradiction by a narrative contrast which is designed to make explicit the semantics of warf ('cast', line 5) as cited by the mediator: Using present tense and deictics which are rooted in the narrated situation, the proponent re-stages the process of the child throwing stones. What matters most to her defense and the semantics of warf/schmei $\beta t^{6}$ ('cast'/'throws') is that she narrates three successive steps of the action:
a. the source: the child starts the action of throwing the stone (line 10);
b. the path: the stone flies half a meter (line 11);
c. the goal: the stone misses the goal (line 12).

By making explicit that the stone did not reach its goal, this iconically designed narrative fragment achieves

a. an exposure of the proponent's meaning: The proponent exposes that the mediator obviously assumes that the proponent meant an accomplishmentinterpretation, i.e. warf ('cast') implies 'reached its goal';

b. the correction of the accomplishment-interpretation by a mere activity-interpretation, ${ }^{7}$ i.e. warf/schmei $\beta t$ ('cast'/'throws') for the proponent only means 'throwing something with the intention of striking a goal.' The activity-interpretation of schmeißst ('throws') is also highlighted by the elision of the prepositional object auf die wäsche ('at the clothes'), which the mediator used in line 4. Since the goal of the action is omitted, the description focuses on the activity itself. So, it also avoids the local ambiguity between a directional interpretation of the preposi- 
tional phrase ('toward the clothes') and an achievement interpretation ('hit the clothes').

The corrective interpretation operates as an interpretation limiter which explicitly denies a semantic feature which the mediator includes in his (local) default interpretation auf warf/schmeißt ('cast'/'throws'). The narrative contrast, marked by awwer ('but', line 12), concedes that there is the expectation of an achievement-interpretation of warf/schmeißst ('cast'/'throws'). This achievement-interpretation, which the proponent attributes to the mediator, and her correcting interpretation are iconically displayed as she contrasts schmeißt ('throws') with the (unexpected) outcome hat $n E t$ getroffe ('did not hit', line 12). The mediator reacts to this statement with a display of scepticism (line 13): He judges the failure to hit the clothes as most unlikely, and thus reinforces his expectation that the meaning of warf/schmeißt ('cast'/'throws') (in this context) implies 'hits the intended target'. Again, the contrast simultaneously works to expose implicit features of the meaning of a prior speaker's formulation and to replace them with next speaker's own corrective interpretation.

The corrective contrast is not restricted to adversative and concessive sequences, it can also be realized by preferential or antithetic constructions. Excerpt (3), which is from the same mediation session as excerpt (2), is an instance of a preferential contrast. The proponent had strongly complained that her opponent's children were rude. In turn, the opponent reproaches the proponent to slander her children in front of her neighbours.

(3) frech [Mediation; IDS-Mannheim 'Schlichtung' 3001/02]

01 Opp: gege meine kinner lass isch mer net rumhetze. I won't have anyone slandering my children.

$02(-)$

03 Pro: sie hawwe e freschs mädl des wisse sie you have an insolent girl you know that

04 ge!NAU! very well

05 Opp: !†ALLE! kinner sin fresch. (.) all children are insolent. (.)

06 liewer hab isch e fresches kind wie e krankes I'd rather have an insolent child than a sick kind. child.

Excerpt (3) contains two corrective contrasts. The first one is:

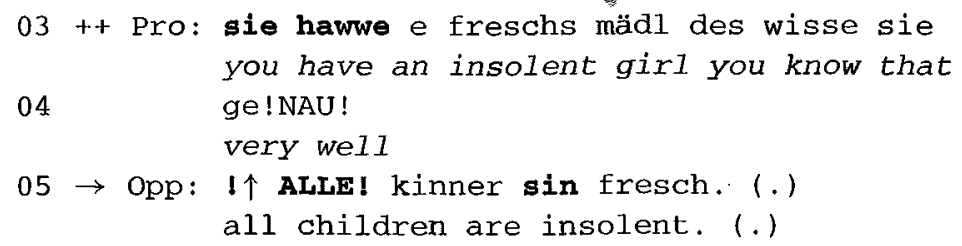


The opponent counters the proponent's reproach by despecifying the semantics of frech ('insolent'). The opponent does not deny the proponent's assertion regarding her children, but she refuses its moral import as a reproach. She does so by choosing a contrasting referential set ('your girl' vs. 'all children') to which she applies the epithet frech ('insolent'). While the proponent categorizes the opponent's child as a member of the subset of insolent children (which implicitly are opposed to well-bred children), the opponent categorizes all children as insolent. Since her formulation eliminates the alternative set of 'well-bred children', which the proponent made relevant by singling out the opponent's daughter, the categorization frech loses its distinctive moral semantics and maybe also its distinctive descriptive power. The contrastive widening of the (locally relevant) extension of frech thus operates as a semantic correction of the proponent's semantics of frech. The correction does not only affect the denotational, but also the moral meaning of the word. It should be noted that in this case the contrast does not alter the meaning of the contrasted words itself: The quantificational contrast $^{8}$ between 'you have an insolent girl' and 'all children are insolent' instead indirectly affects the meaning of the word frech which the contrasted quantities are attributed to. So, part of its meaning is altered by its collocational context, i.e. by the attribution of frech to referential sets which contrast in quantity (i.e. 'one' vs. 'all').

In the same argument sequence, the opponent uses a second contrast to elaborate further on the revaluation of frech ('insolent'):

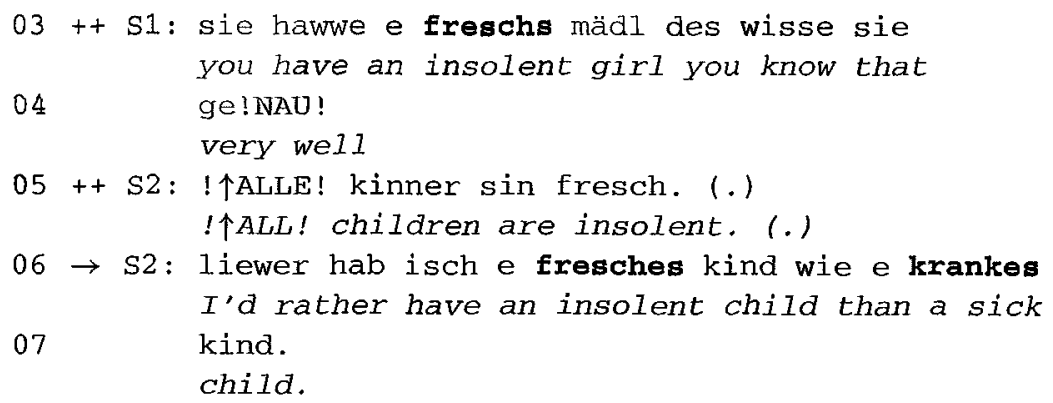

As she tries to keep up her countering position, the opponent, in line 6, resumes the proponent's categorization of her child as frech and establishes a preferential contrast between frech and krank ('sick') with respect to her child. In traditional semantic terms, both predicates would not be regarded as mutually exclusive, but as causally, logically, and semantically unrelated. Consequently, the attribution of one of them to a referent would neither preclude nor project the applicability of the other to the same referent. The preferential contrast, however, does not only express a preference for frech ('insolent') over krank ('sick'). It suggests an alternative or even the need for a choice between the two states 'having an insolent child' and 'having a sick child': Both words are constructed as a locally relevant set of complementaries. Now, contrasted with krank ('sick'), frech ('insolent') obtains a positive semantics, because the contrast highlights possibly relevant interpretations, such as 'vivid', 'healthy', 'self-reliant'. These interpretations were not available in the proponent's original context in line 1 , where 
frech was the upshot of her reproach that the opponent had failed to raise her children properly. In sum, we can trace a passage of the alteration and revaluation of the semantics of frech in this sequence. It proceeds by three steps, all of which crucially rely on contrast structures:

a. S1 (line 3): frech is used derogatively and is distinctively attributed to the opponent's daughter; it means 'bad mannered, not well-bred';

b. S2 (line 5): frech is contrastively attributed to children in general; this accomplishes a semantic despecification by extensional widening and gives frech a morally indifferent value;

c. S2 (line 6): frech is contrastively preferred over krank ('sick'); frech obtains a positive valuation and means 'vivid, healthy, self-reliant etc.'.

\subsection{Inferential bases and interactive functions of the corrective contrast}

All cases of corrective contrast we have considered involve a disagreement between the participants on the local adequacy of a formulation as a descriptive device. In most cases, prior speaker uses the formulation as adequate from his/her point of view. Next speaker then corrects the semantics of the word, because in his/her opinion, prior speaker implied a specific meaning, which s/he expresses by the contrast. Next speaker judges this implicit meaning, which s/he attributes to prior speaker's use of the formulation, as locally inadequate. Therefore s/he refuses the use of the formulation in the way the prior speaker did. The contrast thus rests on inferential reasoning which, schematically, runs as follows:

\section{S1: formulation is adequate;}

S2: formulation as used by $S 1$ is not adequate, because formulation as used by $S 1$ implies a meaning which is not adequate. $^{9}$

This inferential structure is essentially argumentative: Next speaker treats the inadequacy of the inference which s/he draws from prior speaker's use of the word as a reason for the refusal of prior speaker's interpretation.

Corrective contrasts are used to express disaffiliation with a prior speaker's categorization by indicating an account for the disaffiliation. The corrective contrast is a reflexive move, because it accomplishes an activity - a disaffiliating turn - by simultaneously providing grounds for that activity. Corrective contrasts are most prominently used as a means of making disaffiliation accountable by performing a self-explicating disaffiliative action. They may but need not be followed by further explanations or clarifications (excerpt (1) is an example). Corrective contrasts not only oppose a prior turn, but they offer an alternative formulation. Therefore, they do not only decline a projected course of action, but suggest an alternative, or they point to a problem which has to be solved before the previously established joint project can be pursued further. 
This repair-like and reflexive character makes them a potentially productive means of managing interactional disalignment and lack of intersubjectivity.

\section{Explicative contrast: Warranting a deviation categorization}

Corrective contrasts are achieved by a next speaker relating back to a prior speaker's turn. Other practices of contrasting are accomplished by only one speaker. One of them are explicative contrasts. In an explicative contrast, a contrast between two words or phrases is used to explain the local meaning of a third word or phrase and to warrant the relevance and adequacy of the categorization which is accomplished by the use of the third word. Here is an example from a conversation among adolescents. Before excerpt (4) starts, Denis had just told a story about a boy called Vito, who tries to take advantage of others. Now Bernd produces a second story about Vito that aligns with the upshot of the first: Vito is greedy and exploits his friends. ${ }^{10}$

(4) fuir geld (Youth hostel)

01 DC Be: das is mal widder TYPisch vito für geld.

that is TYPical of vito for money.

02 da hätt isch ihn eigentlich wieder GRAD. (--)

I would JUST have him. (-)

03 Rosenmontag ja? (.)

MoNday before lent right? (.)

04 erzählt ex uns die ganze zeit- (.)

he tells all of us again and again- (.)

05 das hat er FüNF mal gesagt

he has said that FIVE times

06 wie GEIL man mit denen- (.)

how FAT you can- (.)

$07++\quad$ ähm guten PARty machen kann; (.)

erm have a good PARty with them; (.)

08 Fr: ja.

yes.

$09 \rightarrow$ Be: und dann RIppt er die voll ab.

and then he really RIPS them off.

10 Fr: darauf hab isch

also last time I

11. [ihn auch das letzte mal drauf

ltalked to him about that

12 De: [was hat er denn gemacht?

[what did he do then?

13 Fr: [angesprochen.

llast time.

$14 \rightarrow$ Be: [RIppt er die voll ab. (-)

[he really RIPS them off. (-) 
ehy das war so hart.

aye it was so hard.

In line 1, Bernd formulates the upshot of the preceding story by categorizing Vito as fiur geld, meaning '(greedy) for money'. Bernd then produces a second story fragment that consists of two contrasting action descriptions: Vito often claimed that he had a good party with some other boys (guten party machen, line 7), whereas later he ripped them off (rippt ab, line 9). ${ }^{11}$ The contrast provides for the upshot of the story fragment and is commented with indignation by Frank and Denis (lines 10-13).

Sequentially, the contrast is delivered as a warrant and simultaneously as a local semantic clarification of the initial categorization für geld in line 1. The basic schema is thus:

S1: deviation categorization is warranted and semantically explained by

$\mathrm{FO}$ but $\mathrm{CO}$

5.1 The deviation categorization and the contrast as display of the violation of an expectation

There is a systematic asymmetry between the two categorizations which are co-selected to construct this type of contrast. The first categorization (here: 'have a party') is positive. This is made clear by explicit positive evaluations (guten ('good'), GEIL ('fat')). Having a party with someone establishes a scenario of shared fun, common activity, and solidarity. The second categorization rippt $a b$ ('rips off') is negative. It is, however, not only intrinsically negative, but what is more interesting, in its sequential environment it is specifically to be heard as a violation of an expectation or a norm that was established by the preceding categorization: to rip the people off with whom you have a party does not fit the scenario of togetherness and solidarity. Bernd's and Frank's indignated comments and repetitions seem precisely to be directed at this violation of a social norm.

The contrasting action descriptions, thus, are a warrant for the relevance and for the adequacy of the initial categorization für geld ('greedy for money', line 1): Someone who acts inconsistently like this is aptly categorized as being 'greedy for money'. It belongs to a type of category I will refer to as 'deviation-categorization'. By a deviationcategorization the speaker indicates that a referent violates a norm or frustrates an expectation that is currently relevant. Deviation categories most importantly include social categories. Examples are nouns such as 'poser' (see excerpt (5)), 'exploiter', 'lier' and their verbal and adjectival variants (cf. Smith 1978: 'mentally ill'). Other deviation categories such as 'broken' (excerpt (8)), 'rancid' or 'old-fashioned' denote objects or abstract entities.

The contrast, however, is not only presented as a warrant. It also functions as a semantic clarification of the local meaning of the deviation-categorization: The contrast instructs the hearer how to specifically interpret the deviation-categorization in 
its interactional environment. Typically, the contrast provides for a referential or extensional specification by describing contrasting actions, states of affair or properties. This specification is often accomplished by some narrative structure which orders the contrasting actions (etc.) in a sequence. As the contrast is a subset of possible contrasts which could serve as a warrant for the deviation-categorization, it does not just specify its reference. It also rules out intensional aspects which the word or phrase may have in other contexts, but does not have in its current use. E.g., 'greedy for money' could imply that a person thus categorized tries to deceive others in order to get their money; this, however, is an interpretation which is not made relevant (although not necessarily excluded) by the explicative contrast in (4).

The following cases provide further examples of the semantic effects and the uses of explicative contrasts. Excerpt (5) is from an interaction among adolescents. Denis and Chris talk about another peer-group member (Markus) who had just been 'dissed', i.e. (more or less) playfully insulted by a peer (cf. Deppermann \& Schmidt 2001). Denis and Chris ridicule Markus as a poser ('poser', line 1), i.e. someone who pretends to be cool and unaffected by being 'dissed'.

(5) poser (Youth center)

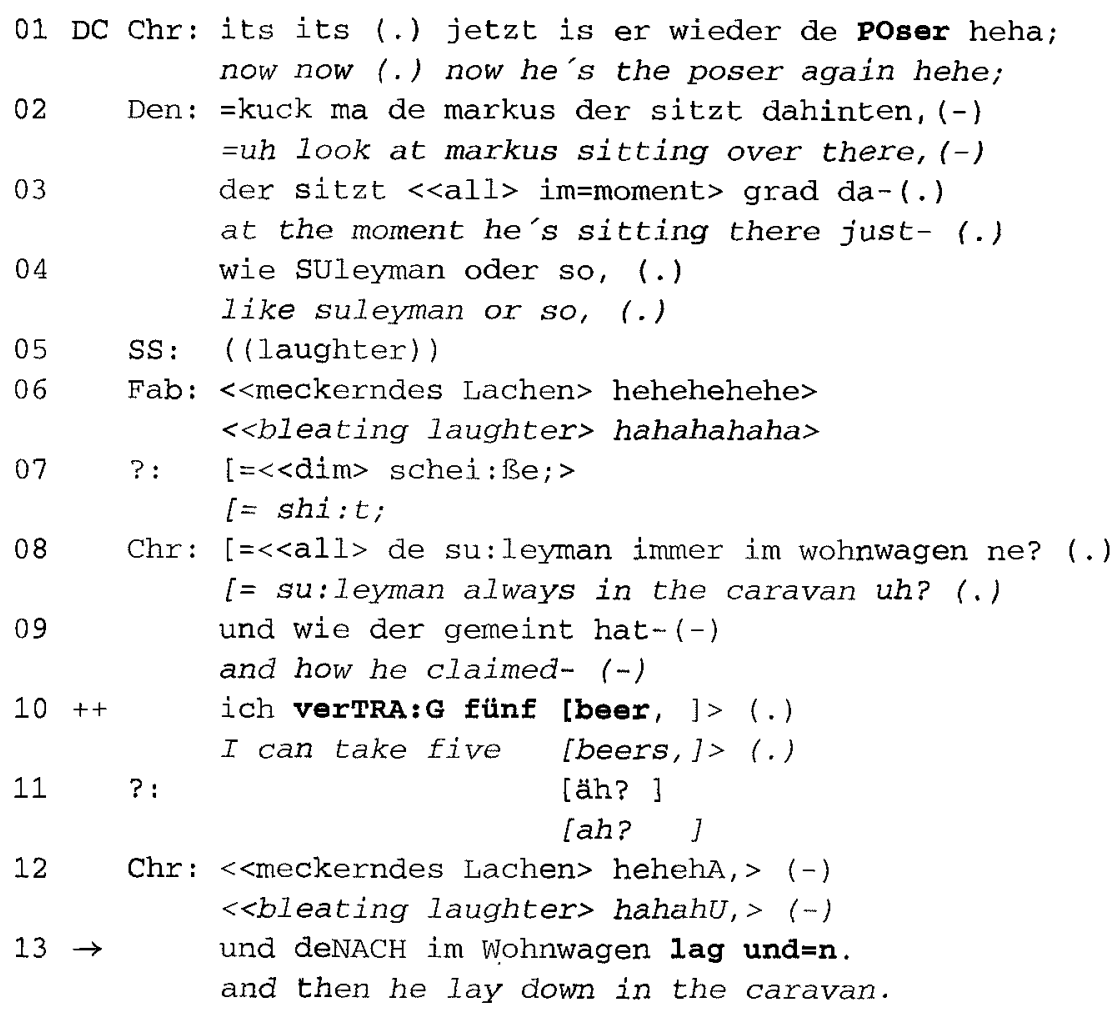

Denis takes a first step of the elaboration of the local semantics of the deviation categorization poser by comparing Markus to another member of the peer-group, Suleyman. 
He is a peripheral, low-status member of the peer-group and is regarded as a braggard. He is thus introduced with a metonymic specification of poser. Starting with line 8, Chris confirms this analogy by telling an episode which attests to Suleyman being a poser. He claimed to be able to take five beers (vertrag fünf bier, line 10), which would be a display of masculinity. This announcement contrasts sharply with the outcome of the consumption: Suleyman lay down in the caravan (lag $u n d=n$, line 13), that is, he was "too weak". This result frustrates the expectation which Suleyman's commissive announcement had established, and so the sequence warrants the deviation-categorization poser. Since the contrast of claim and reality refers to Suleyman, it is an explication of poser - which refers to Markus - by way of an evocative analogy. It highlights semantic aspects such as 'bragging', 'weakness', 'incredible and easy to be discovered façade'. Interpretations of poser that would be salient in other contexts are not supported (such as 'type of heavy-metal freak', 'overdressed').

In excerpt (6), a contrast is constructed in order to account for two different deviation-categorizations. The segment is from a biographical research interview. The interviewee talks about how he felt when he came to West Germany (FRG) in the 1980s as an immigrant from the former German Democratic Republic (GDR). He complains that he was rejected by his West German age-mates ('here') because of his clothing which did not comply with youth cultural fashion standards.

(6) von einem anderen stern (Biographical interview)

IE: un HIER war das natürlich ganz KRASS. and here of course it was very blatant. als AUSländer, (.) as a foreigner, (.) dann ANgezogen wie von einem anderen STERN. then dressed like from another planet.

04 IR: ( (laughs))

05 IE: also ich bin mit SIEBziger JAHre $I$ mean $I$ wore

$06++$ clogs rumgelaufen, (-) clogs in a seventies style, (-) und das mit DREIzehn and that being thirteen years old in neunzehnhundertFüNFundachtzig, nineteeneightyfive,

09 IR: ((laughs))

10 IE: wo die Anderen schon langsam ANgefangen while the others already started

$11 \rightarrow$ haben MARken zu gucken. (-) to look for brands. (-)

12 und DIE:sel gab es damals noch nicht and diesel didn't exist then aber es war halt marco polo oder, but it was just marco polo or, 
IE: benetton.

$$
\text { BEnetton oder marco } \mathrm{PO}: \text { lo. (-) }
$$

benetton or marco polo. (-)

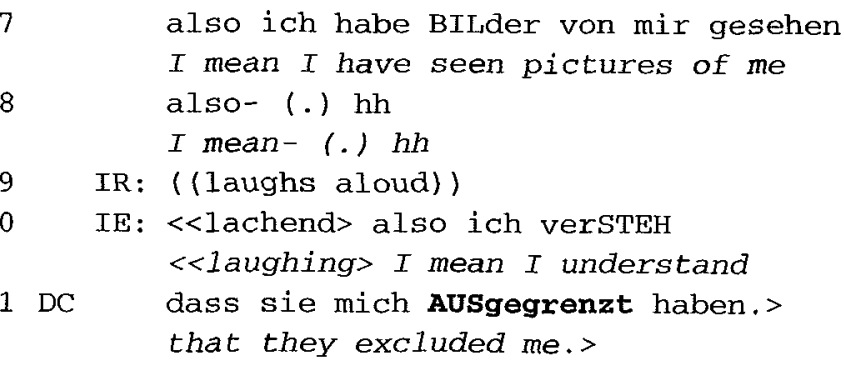

In line 3, the interviewee describes his former dress as like from another planet (angezogen wie von einem anderen stern). This is a visual metaphor for deviation. In what follows, he clarifies this categorization by saying that he wore clogs (lines $5 \mathrm{f}$.), which was an old-fashioned style (siebziger jahre, 'seventies style') at that time. He contrasts this with the preference for marken ('brands', line 11f.), that is, with clothing made by youth-culturally valued producers which adolescents in Germany preferred at that time (neunzehnhundertfiinfundachtzig, '1985', line 8). The contrast with respect to a set of categories for clothing ('clogs' vs. 'brands') thus is co-selected with a contrast of temporal categories ('seventies' vs. ' 1985 '). In contradistinction to excerpts (4), (5) and (7), however, the explicative contrast does not rest on a temporal ordering of contrasted events or actions. Here, it is a majority norm which is established by marken ('brands') and frustrated by clogs. This frustration provides for a comic incongruence which is acknowledged by the story recipient's laughter (line 9). After the interviewee has collaborated with the interviewer in producing examples for brands, he concludes that this contrast was a sufficient reason for Western German boys to exclude him (ausgegrenzt, line 21). The two deviation-categorizations stand in different relations to the explicative contrast:

a. The contrast provides for an extensional and metonymic semantic clarification of the initial deviation-categorization angezogen wie von einem anderen stern ('dressed like from another planet', line 1). This formulaic and metaphorical description is explicated by the contrast of prototypical items (clogs) or properties (brands) which stand metonymically for conflicting styles of dressing.

b. The concluding deviation-categorization ausgegrenzt ('excluded', line 21) is not semantically explicated by the contrast: ${ }^{12}$ It does not provide a specification as to how, where and when exclusion was done and what kind of exclusion is meant. The contrast, however, provides a reason for the activity of excluding. So, the contrast does not explain the categorization ausgegrenzt ('excluded'). Rather, it enhances its intelligibility, but only in an argumentative, not in a semantic, dimension. 
5.2 Projection and restriction of the interpretation of the contrast by a prior deviation-categorization

Explicative contrasts are not only employed to warrant the deviation-categorization. Simultaneously, they specify its local semantic interpretation. In the cases presented, the deviation-category itself is introduced prior to the contrast. However, there are also cases in which a deviation category is presented as a concluding upshot (cf. (6)), and cases in which the contrast is designed to suggest an inference to a deviation-categorization which is not explicitly formulated. The practice of warranting a deviation-categorization is always accomplished by one speaker in a multi-unit turn, which is often projected from its outset. The contrast can therefore be said to be often planned in advance as a narrative device. ${ }^{13}$ It is primarily used as a building block of other genres that are at the same time descriptive and morally implicative, such as gossiping, blaming, or complaining. While the contrast provides for the descriptive core of states, events or actions that warrant a deviation-categorization, the deviation-categorization itself is presented as its moral upshot in the story preface or: in its conclusion. When it is used in a preface which calls for further narrative elaboration, it projects the kind of violations, problems etc. to be told and which the contrast must be understood as being an instance of. The deviation-categorization thus acts as an interpretive restriction which constrains the possible interpretation of the contrasted items.

For example, in (6), the deviation-categorization angezogen wie von einem anderen stern ('dressed like from another planet', line 3) projects an explication of how the teller's clothes differed from his age-mates. This projection also constrains the interpretation of clogs which is used for the teller's own dress - it is projected as being peculiar, negatively valued and inadequate. If the speaker had formulated another preface, clogs could also have been interpreted as reflecting innovation, individuality or health orientation as compared to marken ('brands').

In (5), the deviation-categorization poser (line 1), constrains the interpretation of the contrast, because it pre-establishes an explanation for the contrast between the announcement ich vertrag fünf bier ('I can take five beers') and the result of the consumption lag und $=n$ ('he lay down'). Given the initial categorization poser, the claim to be able to take five beers is clearly to be interpreted as bragging. This restriction would not necessarily be in order, if, e.g., the protagonist had been categorized as 'ill' in the outset.

Explicative contrasts thus serve as a (referential) explication of a deviationcategorization which itself acts as a constraint for the interpretation of the contrast. It does so because it either has an intrinsically contrastive semantics (such as 'poser', 'broken'), which makes contrast strongly expectable, or because it projects a problem, deviation, etc. Since the deviation-categorization and the contrasted categorizations constitute a local set of categories which are to be understood as coherently co-selected, they reciprocally constrain and specify each other's local interpretation. That is, the hearer will select the interpretations for each of them according to the supposition 
that the contrasted items explicate the meaning of the deviation-categorization. The latter in turn restricts the possible interpretations of the contrasted items.

\subsection{Interactional functions of the explicative contrast}

Although explicative contrasts are realized by descriptions, they clearly have an argumentative function and they carry intrinsic evaluations. As such, they differ from the contrasts that Ford $(2000,2001)$ studied: In her data, contrasts were treated as objects in need of explanation or solution. Just on the contrary, explicative contrasts serve as explanations for the use of a deviation-categorization which establishes a complaint etc. This is most obvious when a contrast is delivered only after a disaffiliative hearer's response to a deviation-categorization. In these cases the contrast is interactionally occasioned and not part of a planned explication of a deviationcategorization. Excerpt (7) is a case in question: A child complains that she cannot play the computer game 'Harry Potter', because the computer mouse is kaputt ('broken', deviation-categorization in line 2). Her mother, however, does not align with this assertion and seems to account for the trouble by the child's incompetence to handle the computer correctly: She suggests that the child asks a classmate how to play the game. In lines $8-9$, the child insists on her initial categorization kaputt ('broken') by warranting it with the contrast between her knowledge about the correct handling of the computer and her lack of success.

(7) kaputt (Dinner table conversation)

01 Ch: das harry potter spiel GE:HT wieder NICHT. (.) the harry potter game again does not work. (.)

02 DC IMmer- (-) immer ist die MAU:S kapuTT. (.) always- (-) always the mouse is broken. (.)

03 Mo: du kannst doch den $A-($.$) ANdy anRUFen; (-)$ you can call up A- (.) Andy; (-)

04 der hat dir doch SCHON mal erklärt he already once explained to you

05 WIE das geht. (.) how it works. (.)

06 der weiß es be [STIMMT. he knows lfor sure.

07 Ch: [NEIN NEIN- (-) [no no- (-)

$08++$ ich WEIS wie es geht $-($.

I know how it works- (.)

$09 \rightarrow \quad<<a l l>$ aber es> GE: :HT nicht. but it doesn't work.

$10 \quad(1,0)$

11 Mo: ja:- (.) dann kann ma nichts machen. we1l- (.) then you can't do anything. 
In excerpt (7), there is an interesting fusion of argumentative and semantic concerns which points to the moral implicativity and possibly intrinsic argumentative semantics of deviation-categorizations. The child had first warranted her deviationcategorization kaputt ('broken', line 2) by only referring to the fact that the computer did not work (line 1). The mother's disaffiliative uptake (lines 3-6) points to the fact that a computer does not work may depend on other causes, such as wrong handling. Consequently, the child uses the contrast between correct handling (implicated by ich WEI $\beta$ wie es geht, 'I know how it works', line 8) and (unexpected) malfunction (GEHT nicht, 'doesn't work', line 9) as a refined warrant which is designed to counter the mother's objection because it denies incorrect handling as the cause for the malfunction of the computer. The child makes it explicit that kaputt ('broken') has an argumentative meaning: Its assertive use does not only state the observation about a state of affairs ('something doesn't work'), but it additionally requires a diagnosis of an internal cause for this state ('something doesn't work because of an internal defect'). Although this internal cause is not explicitly asserted, it is strongly implicated by the child's denial of wrong handling which I see as the only contextually salient alternative explanation. The semantic explication therefore serves as an argumentative account and simultaneously points to the causal semantic structure of the deviation-categorization kaputt ('broken'): It not only diagnoses a functional state, but also locates the cause for this state in the object it is attributed to.

To fulfill the function of warranting the deviation-categorization, it is most important to select and combine facts in exactly the way the contrast does: One part of the contrast would not be sufficient, and the function of the contrast would be blocked, if the speaker left open the possibility of further facts that could provide for a normalizing account of the contrasting facts. ${ }^{14}$ So, the explanatory or argumentative value of the contrast needs to be plausible and obvious for its recipients, and the speaker has to take care not to provide for additional descriptions which could serve as a competing explanation that in turn would undermine the deviation-categorization.

\section{Two general interpretive strategies for contrast structures}

Sections 4 and 5 discussed the specific sequential, functional and semantic properties of two practices of contrasting and their impacts on the local interpretation of the words or phrases from which the contrast is built. Still, we have not yet addressed another main issue: How can participants understand words to be local opposites, although there is no common lexical paradigm they are part of? In what follows, I will claim that there are two general strategies for the interpretation of the contrasted items. These are frame-based interpretation and maximization of contrast. These two strategies help to provide the contrasted items with an oppositional meaning, which also specifies their local interpretation in a more comprehensive sense. The use of these two strategies is pervasive with any kind of discursive contrast and seems to be independent of the specific practice of contrasting. 


\subsection{Frame-based interpretation}

Only in some cases of antithesis, discursive contrasts are made up of items which stand to each other in a lexical opposition in the traditional sense (like 'hot' vs. 'cold', 'come' vs. 'go' etc.). In most cases, there is a pragmatic opposition within a frame: ${ }^{15}$ The first item contextualizes a frame of associated expectations which are violated by the contrasted second item. These expectations are systematically tied to the category which is locally made relevant by the first item. The discursive contrast introduces a fact which violates or frustrates some of the expectations that are locally operative because of the first categorization. There are different kinds of expectations which can be frustrated by the contrast.

a. There may be a violation of social norms, such as the violation of an expectation of solidarity and reciprocity in (4), or the deviation from standards of fashion in (6).

b. There may be a violation of causal consequences that can be expected given the antecedents stated. In (2), the action of throwing stones made expectable that they reach their target; however, they did not. Another example of a causal expectation is (7): the correct handling of a device allows for the expectation that the device will work, but here it does not.

In all of these cases, the contrasted words or phrases are not opposed to one another "as such", but with regard to social, instrumental, causal etc. regularities that are contextualized to be locally operative. These background expectations are constitutive of the existence and the intelligibility of the contrast. If they are neither shared nor recoverable, a contrast will not arise for the hearer. Many contrasts are located in temporally ordered frames, i.e. scripts (Schank \& Abelson 1977), which represent a normal course of action or process. This is the case in (2), (4), (5), (7): the first part of the contrast describes an action or a state of affairs that makes strongly expectable a future state or action which is not realized by the second part. So, there is often a second axis of coselection, namely a temporal axis, which systematically combines a temporal sequence of events with the co-selected contrasting items.

Frame-based interpretation does not only provide for the pragmatic opposition between the contrasted categorizations. It also supplies the background knowledge which is necessary to bridge a gap between the facts expressed by the first categorization and those which the contrasting second one represents. For example, in (7), the contrast between ich weiß wie es geht ('I know how it works', line 8) and es geht nicht ('it doesn't work', line 9) needs the bridging assumption (Clark \& Haviland 1977) that the speaker not only knew how to handle the computer correctly, but that she actually did so. Only on this condition, the failure of the computer to work correctly is a relevant frustration of the expectation contextualized by 'I know how it works'. In such cases, the tacit reconstruction and acceptance of such assumptions is decisive for recognizing a contrast. It would not arise, if they were denied or if a competing explanation for the co-occurrence of the first and the second categorization was proposed. 
The background knowledge which is required to grasp the contrasting interpretations can be culturally specific. In (3), line 6 , the preferential contrast between frech ('insolent') and krank ('sick') relies on a folk psychological theory. It says that a child will become sick if exposed to a restrictive education which (only) aims at preventing the child from being insolent. This folk theory has it that there is a conditional and genetic relation between frech ('insolent') and krank ('sick'): If a child is not allowed to be insolent, then it will become sick. The folk theory gives an account for the systematics of why and how frech and krank are contrastively related to one another. This account cannot be gleaned from the interactional sequence itself, it must be supplied by the hearer in order to reconstruct its coherence. Moreover, appeal to this background knowledge is necessary in order to select the right semantic interpretation for the contrasted items. In the context of their contrast and on the basis of the folk psychological theory,

a. frech means 'vivid, clever, self-reliant etc.' - and not 'disobedient', 'uneducated', or 'rude' which was its locally relevant semantics, when frech was used before by the prior speaker in line 1 in the same extract;

b. krank here has to be specified as 'psychologically ill' - and not 'physically ill', 'lying in bed' or 'insane' which it can mean in other contexts.

Another example of how interpretations of contrasted items might depend on a complex frame is (6). Clogs (line 6) and marken ('brands', line 11) do not routinely make up a contrast because any clog can have a brand as its property. ${ }^{16}$ Here, however, wearing clogs is contrasted with wearing brands. Together with the information given about historical and cultural context ('1985', line 8; adolescents in West Germany, lines 1$2,10-11$ ), the recipient can construct a frame of youth-cultural fashion preferences, which allows to fix the local interpretation of clogs and marken ('brands'):

a. 'Brands' occupy the slot of fashionable objects or product-properties. They do not denote a formal product-property which just any brand would be an instance of. Instead, the hearer is forced to construct an autohyponymous interpretation: marken here specifically means 'prestigious in-brands'. This autohyponymous interpretation is further clarified by the examples of relevant brands (diesel, benetton, marco polo), which the participants collaboratively construct in lines 12-16.

b. With respect to the frame of youth-cultural fashion preferences, clogs are not only out of fashion, but further specified as old-fashioned (siebziger jahre, 'seventies', line 5). Clogs can thus be understood as a metonym for 'old-fashioned clothing' and as carrying some additional, more vaguely associated features like 'poor', 'ugly', 'uninformed'. Interpretations of clogs appropriate to other contexts are irrelevant ('healthy'), or at least defocused ('kind of shoe').

These examples show that the local interpretation of words in conversation can essentially depend on ethnographic, historical and other cultural knowledge. Its relevance may be contextualized by linguistic cues with varying degrees of definiteness (cf. Gumperz 1982). 
In sum, the inference to a frame is essential for the reconstruction of the local semantics of the contrasted items. Background knowledge is required in order to understand how and why the second part is pragmatically opposed to the first. Specifically, a frame can

a. be contextualized by one part of the contrast and involve an expectation that is frustrated by the other part,

b. supply bridging assumptions that are necessary to conceive of the elements contrasted as being systematically and contrastively related,

c. relate both parts of the contrast to each other in an explanatory structure,

d. consist of background knowledge that is generally operative for (a stretch of) a conversation and that informs the participants' situated reasoning on which the local semantics of the contrasted items may rely.

\subsection{Maximization of contrast}

Although background knowledge constrains and suggests possible interpretations of contrasted words or phrases, it is not sensitive to the particular fact that they are used as part of a contrast which the speaker produces to be understood as such. So, in (3) the folk psychological theory can supply an explanation of how frech ('insolent') and krank ('sick') might be genetically related to each other (see Section 6.1), but it does not necessarily fix an opposing interpretation of the items. Rather, it seems that the hearer must first recognize the speaker's intention to construct a maximally contrasting interpretation of the items. Maximization of contrast in this case involves several dimensions of meaning:

a. an antonymic evaluation: frech ('insolent') is positively valued, $k$ rank ('sick') negatively;

b. the supposition of incompatibility or even complementarity: 'insolent' seems to imply 'not sick', 'not insolent' seems to imply 'sick'; maybe the speaker even implies that a bi-conditional relation holds, i.e., being 'insolent' and being 'not sick' imply one another;

c. it establishes a negative causal link between the categorizations;

d. it instructs the search for interpretations of both items which maximize such semantic aspects that can be understood as being opposed to each other, such as frech implies 'healthy', while krank implies 'inactive'.

'Maximization' thus means that the hearer is instructed to watch out for and adopt contrasting aspects of meaning as part of the locally relevant interpretation of the contrasted items, while possibly common or unrelated aspects of meaning are defocused as currently irrelevant or even as locally invalid. Frech ('insolent') vs. krank ('sick'), for instance, could in other contexts both be evaluated as negative characteristics, which are dispreferred and should be fought by parents, and they could even be positively 
related to one another by a competing folk psychological theory that sees sickness as a just punishment for being insolent. ${ }^{17}$

Contrasted items affect one another reciprocally in their interpretation, i.e., their specific local interpretations mutually depend on each other. ${ }^{18}$ In fact, the hearer first needs to recognize that the speaker intends to convey an asymmetric evaluative contrast in order to choose the right folk psychological frame within which s/he can interpret frech and krank. If s/he did not recognize that a contrast was intended, there may be quite different ways to relate the items to each other, and some of them would entail very different interpretations for them.

A similar reasoning that maximizes the contrast is necessary for a correct understanding of most of the examples discussed, e.g.:

- In (6), und =n liegen ('to lie down') needs to be specified as 'loss of self-control and bad physical condition', for this is exactly the opposite of 'unimpeded self-control and physical condition' which was implied by the contrasting claim ich vertrag fiinf bier ('I can take five beers').

- In (7), clogs and marken ('brands') have to be understood as polar antonyms with respect to a scale of 'being fashionable.' This in turn forces clogs into a metonymic interpretation and marken into an autohyponymic sense (cf. Section 6.1).

In general, we can posit a 'maxim of the maximization of contrast': If the hearer recognizes that the speaker intends to contrast two words, then s/he interprets them so as to maximize their contrast in meaning. I will briefly comment on parts of this formulation:

The reference to the recognition of the speaker's intention is most central because it instructs the hearer to look for cues that can be used to constitute or contextualize a contrast. ${ }^{19}$ Once this intention is recognized, the hearer will not only recognize that the contrasted items somehow do not fit together, but s/he realizes that they are systematically co-selected in order to convey a deliberate contrast to an expectation. The instruction to maximize the contrast implies that the hearer should maximize the ways in which they are contrastively relevant to each other. This involves that the contrasted words or phrases are related to one another with respect to a common frame, that the hearer actively looks for motivational, instrumental, causal etc. links which can explain the co-occurrence of the contrasted states, and that $\mathrm{s} /$ he does not assume the existence of unstated facts which would eliminate the contrast. Finally, the appeal to maximize the contrast in meaning instructs the hearer to look for common semantic dimensions on which the two items can be located as inhabiting opposing (polar, complementary etc.) positions. This preference for maximizing contrasts in meaning is reflected by the fact that the contrasting items are routinely associated with an asymmetric evaluation, that is, if contextually suitable, one of them is interpreted as being positive, the other as being negative.

The maxim guides the selection, foregrounding and construction of local interpretations for the contrasted items among the range of otherwise contextually and lexically possible interpretations. Other interpretations which would be possible, but 
which focus on common or unrelated semantic properties, are disfavoured. Instead, the maxim works as a heuristics which instructs the hearer to construct new meanings that have not been associated before with one of the words (phrases) or even both of them.

The maxim of maximizing the contrast is reminiscent of Sacks' (1972) hearer's maxim for the co-selection of categorizations. Sacks' maxim instructs the hearer to interpret subsequent categorizations consistently as belonging to the same membership categorization device (MCD) as a first one (if possible). Sacks' maxim has a number of interpretive consequences that parallel those of the maxim of maximizing the contrast, namely, the maximization of coherence between categorizations, the supposition of a systematic choice by the speaker and the incorporation into a common frame. ${ }^{20}$

The maxim of the maximization of the contrast is also a corollary of the second Gricean maxim of quantity: "Don't make your contribution more informative than is required" (Grice 1975) in its interpretation by Levinson (2000: 112ff.), who calls it the "Principle of Informativeness". It instructs the hearer to interpret an utterance as specific as possible, that is, as maximally fulfilling the speaker's communicative intention as reconstructed by the hearer. This principle makes the hearer suppose that stereotypical, frame-based knowledge can be used in order to amend, enrich, disambiguate, and connect the speaker's descriptions in order to maximize coherence. It also suggests that there are no unstated facts which would thwart the reconstructed intentional upshot.

\section{Conclusion}

Contrasting in conversation is not one homogeneous practice. In my paper, I have focused on two variants that differ in their ways of providing contrasted words with a specific local interpretation: Correcting a prior categorization and warranting a deviation-categorization. Furthermore, I have tried to show that there are two general strategies of interpreting contrasted lexical items as semantically contrasting needed in order to arrive at a contrastive local interpretation: Frame-based interpretation and maximization of contrast. These strategies are applied regardless of the specific kind of practice by which the contrast is accomplished. Speakers use conversational activities and background knowledge to construct locally specific interpretations of lexical items. I tried to show that and - at least in some basic ways - how both sources of interpretation are needed and made relevant by each other in order to achieve local semantic interpretations. ${ }^{21}$ This study is thus an empirically backed plea for the integration of conversation analytic and cognitive approaches in the study of interactional linguistics, especially for concerns of semantics and meaning construction.

As to the relation of lexical and conversational structure, this study reveals that locally relevant semantic contrasts may be accomplished ad hoc by activities of contrasting. Looking ahead, it also suggests that conversational contrasting may have its effects on lexical structure, at least in the long run: Lexical contrasts might ultimately rely on conversational contrasts that have been used routinely. A pervasive, repeated, 
routine use of conversational contrasts may provide lexical items with an interpretation which becomes available "out of context", that is, independent of the activity of contrasting. ${ }^{22}$ The lexical item may then be said to incorporate the meaning potential which was supplied by instances of discursive contrasting as a salient possibility of interpretation, that is, it somehow absorbs its opposite as the relevant frame of interpretation as a meaning potential. This can be used in other contexts without the need to be re-instated by manifest contrasts. Further studies on the history of the contrasting use and the meaning of lexical items will be necessary to show whether this genetic hypothesis about semantic change holds. If it turns out to be right, the interactional linguistic claim that routine interactional activities petrify as linguistic structure would also be given a basis in the realm of semantics.

\section{Notes}

* I thank Peter Auer, Dagmar Barth-Weingarten, Auli Hakulinen and Margret Selting for valuable comments on an earlier version of this paper.

1. Sweetser (1990) also states these two shortcomings of structuralist semantics from a cognitive-pragmatic viewpoint.

2. In most of the following examples the participants use Southern German dialects. For the transcription conventions used here see Selting et al. (1998).

3. In the transcripts, first parts of contrasting formulations are marked by ++ , while second parts are indicated by arrows $(\rightarrow)$.

4. The vagueness of "adequacy" is intentional, because there may be very different matters at issue, such as truth, evaluation, applicability, precision of prior speaker's formulation.

5. Excerpts (2) and (3) are data from the corpus "Schlichtungsgespräche" ('Mediation sessions') of the Institut für Deutsche Sprache (Institute for German Language, Mannheim/Germany).

6. The German verbs werfen und schmeißen are denotationally perfectly synonymous when used as a predicate taking the direct object stein ('stone'). The use of schmeißen, however, is restricted to orality. It may be that the reformulation of warf (line 5) as schmeißt (line 10) serves to adumbrate a semantic difference and thus is not merely a paraphrase. However, the semantic correction only becomes evident as the proponent negates the expected result of the action in line 12.

7. The distinction between accomplishment- and activity-interpretation is made by Pustejovsky (1995: 12).

8. Note that a contrastive accent is put most emphatically on !ALLE! ('all'), thus stressing the quantificational contrast.

9. The inferential structure is slightly different in the case of the preferential contrast frech ('insolent') vs. krank ('sick') in excerpt (3). Here, the participants do not disagree whether frech is an adequate attribution to the opponent's daughter. Rather, they disagree on its evaluation: While the proponent evaluates frech negatively, the opponent uses the contrast with krank to point to the inference that frech has to be evaluated positively.

10. The deviation categorization is indicated by 'DC' in the transcripts. 
11. It turns out later that this refers to the fact that Vito consumed large quantities of the other boys' drugs.

12. It is only explained later in the interview.

13. I found only one case in which a contrast warranting a deviation-categorization was produced by two speakers. However, in that specific case, the second speaker was only bringing out a contrast in the clear that had already been adumbrated by the first speaker. Such a case can be understood as an eminent display of shared knowledge and shared attitudes towards a person or an object.

14. This could be shown for all cases discussed. For instance, in (5), other causes than Suleyman's consumption of beer may have made him lie down in the caravan; or in (7), the mouse might not have been branched correctly etc.

15. The notion 'frame' (Fillmore 1982, 1985; Barsalou 1992) is used here as a cover term that encompasses different models of knowledge structures which have been claimed to account for inferential processes of situated understanding. Among them are concepts like 'frame', 'schema', 'scenario' and 'script'. For the present concerns, differences in notation, internal structure, representational format, inferential procedures etc. between these models are of minor importance. It has to be noted, however, that frames here are not regarded as fixed knowledge structures which are invariably associated with a specific word. Rather, they are conceived of as context-dependent structures, which can be flexibly adapted to contextual information, may be reworked and constructed on the spot (cf. Barsalou 1992) and are subject to processes of spreading activation (Herrmann et al. 1996).

16. In a representation of the standard-meaning of clogs, 'brand' would be an 'is a'-slot, which would be instantiated differently for clogs from different producers.

17. Moreover, to be insolent can be considered as a kind of social illness, or physically sick children can be said to be less insolent, etc.

18. This is different with cases like (2), where nicht getroffe ('did not hit') does affect schmeißt ('throws'), but in turn is not affected by the latter.

19. This should not be mistaken as a plea for a mentalist stance of analysis or even as a supposition that the hearer could inspect the speaker's intentions. The emphasis on the requirement to recognize the speaker's intention points to the fact that the hearer needs to ascribe an intention to the speaker in order to understand his/her turns as intelligible and purposive contributions to a conversation and that s/he does so by interpreting the speaker's public activities in terms of intentional actions.

20. The notion of 'MCD' can be accomodated to the concept of 'frame'. In its collection-like, taxonomic and paradigmatic character, however, it is more restricted than other kinds of frames, which also allow for causal, instrumental, moral, rational, etc. links between their elements and which explicitly focus on the inferential (default-)reasoning connections between their elements.

21. In fact, "activities" cannot be recognized as such without bringing relevant background knowledge to the fore, whereas the relevant knowledge needs to be cued and validated by ongoing conversational activities.

22. The interpretation of frech ('insolent') seems to be a case in question: Its opposition to krank ('sick') meanwhile is "routinely relevant" and exploited in a variety of uses, where there is no manifest contrast. 


\section{References}

Atkinson, John Maxwell (1984). Our masters' voices. London: Methuen.

Barsalou, Lawrence W. (1992). "Frames, concepts, and conceptual fields." In Adrienne Lehrer \& E. F. Kittay (Eds.), Frames, fields, and contrasts (pp. 21-74). Hillsdale: Lawrence Erlbaum.

Barth-Weingarten, Dagmar (2003). Concession in spoken English. On the realisation of a discourse-pragmatic relation. Tübingen: Narr.

Clark, Herbert H. \& Haviland, Susan E. (1977). "Comprehension and the given-new contract." In Freedle, Roy O. (Ed.), Discourse production and comprehension (pp. 1-40). Hillsdale: Lawrence Erlbaum.

Couper-Kuhlen, Elizabeth \& Thompson, Sandra A. (2000). "Concessive patterns in conversation." In Elizabeth Couper-Kuhlen \& Bernd Kortmann (Eds.), Cognitive and discourse perspectives on cause, condition, concession and contrast (pp. 381-410). Berlin: de Gruyter.

Cruse, D. Alan (1986). Lexical semantics. Cambridge: Cambridge University Press.

Deppermann, Arnulf \& Schmidt, Axel (2001). "Disrespecting: A conversational practice for the negotiation of status in juvenile peer-groups." In Németh, Enikö (Ed.), Pragmatics in 2000: Selected papers from the 7th International Pragmatics Conference. Vol. 2 (pp. 156-164). Antwerpen: International Pragmatics Association.

Drew, Paul (1992). "Contested evidence in courtroom cross-examination: The case of a trial for rape." In Paul Drew \& John Heritage (Eds.), Talk at work (pp. 270-320). Cambridge: Cambridge University Press.

Edwards, Derek (1997). Discourse and cognition. London: Sage.

Edwards, Derek (1998). "The relevant thing about her: Social identity categories in use." In Charles Antaki \& Sue Widdicombe (Eds.), Identities in talk (pp. 15-33). London: Sage.

Fauconnier, Guy (1985). Mental spaces, Cambridge: MIT.

Fillmore, Charles C. (1982). "Frame semantics." In The Linguistic Society of Korea (Ed.), Linguistics in the morning calm. Selected papers from SICOL-1981 (pp. 111-137). Seoul: Hanshin.

Fillmore, Charles J. (1985). "Frames and the semantics of understanding." Quaderni di Semantica, 6(2), 222-254.

Ford, Cecilia E. (2000). "The treatment of contrasts in conversation." In Elizabeth CouperKuhlen \& Bernd Kortmann (Eds.), Cognitive and discourse perspectives on cause, condition, concession and contrast (pp. 285-310). Berlin: de Gruyter.

Ford, Cecila E. (2001). "At the intersection of turn and sequence: Negation and what comes next." In Elizabeth Couper-Kuhlen \& Margret Selting (Eds.), Studies in Interactional Lingustics (pp. 51-79). Amsterdam: John Benjamins.

Grice, H. Paul (1975). "Logic and conversation." In Peter Cole \& James Morgan (Eds.), Syntax and semantics. Vol. 3 (pp. 41-58). New York: Academic Press.

Günthner, Susanne (2000). "From concessive connector to discourse marker: The use of obwohl in German interaction." In Elizabeth Couper-Kuhlen \& Bernd Kortmann (Eds.), Cognitive and discourse perspectives on cause, condition, concession and contrast (pp. 439-467). Berlin: de Gruyter.

Gumperz, John J. (1982). Discourse strategies. Cambridge: Cambridge University Press.

Heritage, John (1995). "Conversation analysis. Methodological aspects." In Uta M. Quasthoff (Ed.), Aspects of oral communication (pp. 391-408). 'Berlin: de Gruyter. 
Herrmann, Theo, Grabowski, Joachim, Schweizer, Karin, \& Graf, Ralf (1996). "Die mentale Repräsentation von Konzepten, Wörtern und Figuren." In Joachim Grabowski, Gisela Harras, \& Theo Herrmann (Eds.), Bedeutung, Konzepte, Bedeutungskonzepte (pp. 120-152). Opladen: Westdeutscher Verlag.

König, Ekkehard \& Siemund, Peter (2000). "Causal and concessive clauses: Formal and semantic relations." In Elizabeth Couper-Kuhlen \& Bernd Kortmann (Eds.), Cognitive and discourse perspectives on cause, condition, concession and contrast (pp. 341-360). Berlin: de Gruyter.

Lakoff, Robin Tolmach (1971). "If's, and's, and but's about conjunction." In Charles J. Fillmore \& D. Terence Langendoen (Eds.), Studies in linguistic semantics (pp. 114-149). New York: Holt, Rinehart and Winston.

Levinson, Stephen C. (2000). Presumptive meanings. The theory of Generalized Conversational Implicature. Cambridge: MIT.

Longacre, Robert E. (1983). The grammar of discourse. New York: Plenum.

Lyons, John (1977). Semantics. Vol. 1. Cambridge: Cambridge University Press.

Mann, William C. \& Thompson, Sandra A. (1992). "Relational discourse structure: A comparison of approaches to structuring text by 'contrast." In Ja J. Hwang Shin \& William R. Merrifield (Eds.), Language in context: Essays für Robert E. Longacre (pp. 19-45). Dallas: Summer Institute of Linguistics and The University of Texas at Arlington.

Pustejovsky, James (1995). The generative lexicon. Cambridge: MIT Press.

Rudolph, Elisabeth (1996). Contrast: Adversative and concessive relations and their expression in English, German, Spanish and Portuguese on sentence level and text level. Berlin: de Gruyter.

Sacks, Harvey (1972). "On the analyzability of stories by children." In John J. Gumperz \& Dell Hymes (Eds.), Explorations in the ethnography of speaking (pp. 324-345). New York: Holt, Rinehart and Winston.

Schank, Roger C. \& Abelson, Robert Paul (1977). Scripts, plans, goals and understanding. Hillsdale: Lawrence Erlbaum.

Selting, Margret, Auer, Peter, Barden, Birgit, Bergmann, Jörg, Couper-Kuhlen, Elizabeth, Günthner, Susanne, Meier, Christoph, Quasthoff, Uta, Schlobinski, Peter, \& Uhmann, Susanne (1998). "Gesprächsanalytisches Transkriptionssystem (GAT)." Linguistische Berichte, 173, 91-122.

Smith, Dorothy (1978), "“K is mentally ill": The anatomy of a factual account." Sociology, 12, 23-53.

Sweetser, Eve E. (1990). From etymology to pragmatics. Cambridge: Cambridge University Press. Thompson, Sandra A. \& Mann, William C. (1987). "Antithesis: A study in clause combining and discourse structure." In Ross Steele \& Terry Threadgold (Eds.), Language topics: Essays in the honour of Michael Halliday. Volume II (pp. 359-381). Amsterdam: John Benjamins. 